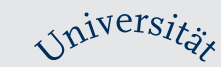

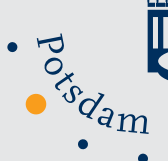

Humanwissenschaftliche Fakultät

Viola Meckelmann | Caroline Pfeifer | Hellgard Rauh

\title{
Family relationships in childhood, pubertal timing, and subsequent reproductive strategies among adolescents
}

Suggested citation referring to the original publication:

South African Journal of Psychology 43(1) (2013). pp. 22-33

DOI http://dx.doi.org/10.1177/0081246312474408

ISSN (online) 2078-208X

ISSN (print) 0081-2463

Postprint archived at the Institutional Repository of the Potsdam University in:

Postprints der Universität Potsdam

Humanwissenschaftliche Reihe ; 373

ISSN 1866-8364

http://nbn-resolving.de/urn:nbn:de:kobv:517-opus4-403611 



\title{
Family relationships in childhood, pubertal timing, and subsequent reproductive strategies among adolescents
}

\author{
Viola Meckelmann, Caroline Pfeifer and Hellgard \\ Rauh
}

\begin{abstract}
The evolutionary theory of socialization of Belsky, Steinberg, and Draper was investigated on the empirical basis of a longitudinal sample of 26 adolescent girls and boys who were born in Berlin during German reunification, as well as their mothers. Consistent with the theory, pubertal timing of the girls (but not of the boys) was predicted by the quality of parental relations in childhood, and pubertal timing of the girls (but not of the boys) was a significant predictor of the age at first intercourse. The results suggest that there are different developmental pathways for girls and boys with respect to the predictions of the evolutionary theory of socialization of Belsky et al. The findings also support the hypothesis that early onset of reproduction and frequent reproduction may be two different aspects of a quantitative reproductive strategy.
\end{abstract}

\section{Keywords}

Adolescence, childhood, family relations, pubertal timing, puberty, reproductive strategies

Pubertal timing is currently being discussed as an important factor with regard to psychosocial adjustment in adolescence. Based on the fact that "there is substantial variation in the timing of puberty" (James, Ellis, Schlomer, \& Garber, 2012, p. 687), recent research (Hayward, 2003; Weichold \& Silbereisen, 2008) has focused on the antecedents of pubertal timing and its consequences for psychosocial adjustment in adolescence. The majority of recent research has investigated the consequences of pubertal timing for psychosocial adjustment in adolescence, and in recent years, a growing number of studies have focused on the antecedents of pubertal timing (see,

University of Potsdam, Germany

\section{Corresponding author:}

Viola Meckelmann, Department of Psychology, University of Potsdam, Karl-Liebknecht-Str. 24-25, I4476 Potsdam, OT Golm, Germany.

Email: viola.meckelmann@uni-potsdam.de 
for review, Ellis, 2004, 2005; Graber, 2003). Investigations continue into factors that may impact the timing of pubertal development, such as nutrition, exercise, socioeconomic status, ethnicity, and psychosocial stress. The following studies analyzed both genetic factors and family context conditions in childhood as possible determinants of pubertal timing in adolescence (Ellis \& Essex, 2007; Hoier, 2003a, 2003b; Keller \& Chasiotis, 2006; Neberich, Penke, Lehnhart, \& Asendorpf, 2010; Tither \& Ellis, 2008). Ellis (2005) reported that "poverty was found to forecast later pubertal development, while family dysfunction predicted earlier development" (p. 181). The evolutionary theory of socialization articulated by Belsky, Steinberg, and Draper (1991a) is presently also being discussed as one possible evolutionary developmental model that may predict the relationships between family context conditions in childhood, pubertal timing, and subsequent reproductive strategies among adolescents.

\section{The evolutionary theory of socialization of Belsky et al. ( 199 Ia)}

The theory is based on the "central premise ... that natural selection has shaped pubertal and subsequent sexual and pair-bonding processes to be responsive to contextual conditions of childhood" (Belsky, Steinberg, \& Draper, 1991b, p. 682). The authors proposed that "a principal evolutionary function of early experience - the first 5-7 years of life - is to induce in the child an understanding of the availability and predictability of resources . . . in the environment, of the trustworthiness of others, and of the enduringness of close interpersonal relationships, all of which will affect how the developing person apportions reproductive effort" (Belsky et al., 1991a, p. 650). Based on these assumptions, the authors theorized two distinct prototypical developmental pathways: a quantitative reproductive strategy and a qualitative reproductive strategy. Family "contextual stressors, among them, marital discord, single parenthood, and unstable employment ... [should] foster more insensitive, harsh, rejecting, inconsistent, and/or unpredictable parenting behavior. This, in turn . . [should] induce in the child" an insecure attachment (Belsky et al., 1991a, p. 651). According to the postulated quantitative reproductive strategy, high levels of family stressors in childhood (e.g. father absence, scarce or instable resources, negative parental relations) should be associated with earlier onset of puberty, earlier sexual activity, short-term and unstable pair-bonds, and lower levels of parental investment (in terms of parenting effort). In contrast, the postulated qualitative reproductive strategy predicts that positive developmental conditions within the family during childhood (e.g. support, stability, warmth) should be associated with later onset of puberty, later sexual activity, long-term and enduring pair-bonds, and high levels of parental investment. Furthermore, Belsky (1999) assumed that "patterns of attachment served as vehicles for "translating' information about prevailing ecological conditions into a fitness enhancing reproductive strategy" (p. 149). The evolutionary theory of socialization of Belsky et al. (1991a) is also referred to currently as "psychosocial acceleration theory" (Ellis, 2005, p. 172).

\section{Empirical evidence}

With regard to pubertal timing, prior longitudinal research findings support these hypothesized predictions between family stressors in childhood and an earlier timing of puberty, especially in girls (Belsky et al., 2007; Belsky, Steinberg, Houts, \& Halpern-Felsher, 2010; Chasiotis \& Keller, 1995; Ellis \& Garber, 2000; Ellis, McFadyen-Ketchum, Pettit, Dodge, \& Bates, 1999; James et al., 2012; Meckelmann, 2008; Moffitt, Caspi, Belsky, \& Silva, 1992; Saxbe \& Repetti, 2009; Tremblay \& Frigon, 2005). In line with the theory of Belsky et al. (1991a), there is empirical evidence that 
indicates that father absence, socioeconomic stressors, and negative parental relations are potentially significant predictors of earlier pubertal timing.

With respect to father absence, Surbey (1998) found in her retrospective study of women that girls who grow up with father absence and with high levels of stress in childhood experience menarche at an earlier age. Bogaert (2005) also retrospectively investigated the relations between father absence and pubertal timing in women and men. He found that father absence at age 14 predicted an earlier age of puberty onset in both girls and boys. In a retrospective survey of men by Kim and Smith (1998), father absence in childhood was associated with earlier spermarche. In line with these findings, Chasiotis (1999) reported, also in the context of a retrospective study, that earlier puberty in men was associated with father absence (divorce) and scarce financial resources in childhood.

Furthermore, Ellis and Garber (2000) proposed that the presence of a stepfather (i.e., exposure to the pheromones of unrelated males) and stressful family relationships constitute separate developmental pathways to earlier pubertal timing in girls. Hoier (2003a, 2003b) also investigated the relation between father absence and age at menarche in a retrospective study of women. Her results indicate that the number of years in childhood without a father figure (biological father or stepfather) predicted an earlier age at menarche. Neberich et al. (2010) were able to replicate this finding. In addition, these results are empirically supported by the genetically and environmentally controlled sibling study by Tither and Ellis (2008). They found that "early exposure to disordered paternal behaviour, followed by family disruption and residential separation from the father, can lead to substantially earlier menarche" (Tither \& Ellis, 2008, p. 1409).

There are only a few prospective longitudinal studies that have focused on the effect of parental relations on pubertal timing among both girls and boys (Belsky et al., 2007; Ellis \& Essex, 2007). Belsky et al. (2007) showed that more negative rearing conditions in childhood predicted earlier pubertal timing in girls but not in boys. On the contrary, Ellis and Essex (2007) found that a higher quality of parental investment predicted later adrenarche ${ }^{1}$ in their sample of girls and boys. The results of the retrospective study by Kim and Smith (1998), conducted among women and men, also indicated that more parental marital conflict in childhood was associated with earlier menarche and earlier spermarche.

With regard to pubertal timing and subsequent reproductive strategies, only a few studies, most of them retrospective, have tested the predictions of Belsky et al. (1991a), and mostly for girls. These studies report some empirical suggestions that are in line with the hypothesized predictions. Hoier (2003a, 2003b), Neberich et al. (2010), and Surbey (1998) found in retrospective studies of women that an earlier age at menarche was associated with an earlier age at first sexual intercourse. In retrospective studies of men, Kim and Smith $(1998,1999)$ found that earlier age at spermarche was associated with earlier age at first sexual intercourse, and Chasiotis (1999) reported associations between the pubertal growth spurt and age at first sexual intercourse. However, only some of these retrospective studies found associations between an earlier age at puberty and more boyfriends or girlfriends in adolescence (Kim \& Smith, 1998, 1999, in women and in men) and more sexual partners (Chasiotis, 1999, in women). Recently, Belsky et al. (2010) tested predictions between early maternal harshness, earlier menarche, and increased sexual risk taking (including the number of times the adolescent had sex) in a prospective longitudinal study. Greater maternal harshness predicted an earlier age at menarche, and earlier menarche predicted greater sexual risk taking.

Meckelmann (2008) also examined the above-hypothesized predictions between family stressors in childhood, pubertal timing, and subsequent reproductive strategies in adolescent girls in a prospective longitudinal study. She found that earlier pubertal timing was predicted by parental marital stress and by a more negative quality of the girls' relationships to their mothers. In her 
study, earlier pubertal timing also predicted earlier age at first sexual intercourse, but no significant association could be found between pubertal timing and the number of sexual partners.

In sum, despite empirical evidence that supports the hypothesized predictions of the evolutionary theory of socialization of Belsky et al. (1991a), especially in girls, only a few prospective longitudinal studies have considered the course of development from childhood to adolescence by including as variables antecedents of pubertal timing, the onset of puberty, and subsequent reproductive strategies (see also Belsky et al., 2010; James et al., 2012). Moreover, in this research field, there is a lack of studies that consider the development of both girls and boys.

The aim of this study was to investigate, on the longitudinal empirical basis of a sample of 26 adolescent girls and boys, the predictions of the evolutionary theory of socialization of Belsky et al. (1991a). Specifically, this study posed the following research questions: (1) Are family stressors in childhood (father absence, socioeconomic stressors, negative parental relations) significant predictors of earlier pubertal timing among adolescents? (2) Is pubertal timing of adolescents a significant predictor of age at first intercourse and of the number of sexual partners? (3) Do the results differ by gender?

Based on the predictions of the evolutionary theory of socialization of Belsky et al. (1991a), we expected that (1) family stressors in childhood (father absence, socioeconomic stressors, negative parental relations) are significant predictors of earlier pubertal timing among adolescents, (2) pubertal timing among adolescents is a significant predictor both of age at first intercourse and of the number of sexual partners, and (3) the results should not differ by adolescent gender.

\section{Method}

\section{Participants}

The participants of this study were 26 adolescents who were born in Berlin during the period of German reunification. Of these, 17 participants were born in the former West Berlin (10 girls and 7 boys), and 9 participants were born in the former East Berlin ( 3 girls and 6 boys). They are a subset of the sample in the German Research Foundation (Deutsche Forschungsgemeinschaft, DFG) project entitled "Berliner Wendekinder" (Rauh, Weber, Feger, \& Doerfel-Baasen, 1999). ${ }^{2}$ In the context of this study, we questioned our sample once again in a follow-up to the original "Wendekinder" project. Thus, the participants were investigated prospectively in childhood (at age 6 ) and, in 2007, in adolescence (mean age: $M=17.74$, standard deviation $[S D]=0.63$ ). The sample consisted of 13 girls (mean age: $M=17.49, S D=0.62$ ) and 13 boys (mean age: $M=17.99, S D=$ 0.55). Participating mothers had comparable levels of education. In childhood (maternal report at age 6 of the child), 10 girls and 12 boys lived together with both biological parents, whereas 3 girls and 1 boy lived with only their biological mothers in a household without their father (there was no case of a stepfather). The interviews and questionnaires took place at the families' homes, and the adolescents were surveyed separately from their mothers. The adolescents completed questionnaires themselves.

\section{Ethical considerations}

The participants of this study were informed of the nature and the goal of the study. Participation was on a voluntary basis and the participants could withdraw from the study at any time. They were also informed of their confidentiality and anonymity in the safekeeping of the research data and the reporting of the findings. In accordance with the Berlin Data Protection Act, the parents of all 26 
participants provided written informed consent for their own and their children's participation (for the first survey, as well as the subsequent survey in 2007).

\section{Measures}

Socioeconomic stressors in childhood. When the child was 6 years of age, mothers were asked about socioeconomic stressors in the family over the first 6 years of the child's life. The following stressors regarding financial resources, occupation, and housing were assessed: scarce financial resources, changing residence, the mother's occupational changes, the father's occupational changes, and the mother's occupational problems. Each of these five stressors was asked for different times of the child's life (separately for age 1 of the child, for ages $2-4$, and for ages 4-6), 1 (yes), 0 (no). All stressors were summarized and cumulated over the first 6 years of the child's life $(M=4.33, S D=2.28$, range 8.00).

Parental relations in childhood. Parental relations in childhood were assessed retrospectively by the adolescent girls and boys. The Relationship Context Scale (BKS; Scheffer, Chasiotis, Restemeier, Keller, \& Schölmerich, 2000) was used to assess the quality of the parents' marital relationship and the quality of the child's maternal relationship. The subscale quality of the parents' marital relationship consisted of five items. Participants were asked, "How accurately do the following terms describe your parents' marriage during your first eight years of your life?"; sample items included "happiness" and "understanding." The subscale quality of maternal relationship consisted of six items. Participants were asked, "How accurately do the following terms describe your mother's behaviour towards you during the first eight years of your life?"; sample items included "love" and "understanding." Participants rated the items on a 4-point scale from 1 (not at all) to 4 (very accurate). In the current sample, Cronbach's $\alpha$ for the quality of the parents' marital relationship and for the quality of the maternal relationship were .87 and .82 , respectively. Cronbach's $\alpha$ for the BKS was $\alpha=.92$ (Scheffer et al., 2000, p. 3). The authors also reported "highly valid results" (p. 3).

Pubertal timing. Pubertal timing data were collected retrospectively from adolescent girls and boys. Relative pubertal timing was assessed using a question from the Pubertal Developmental Scale (PDS; Petersen, Crockett, Richards, \& Boxer, 1988; see also Fend, 1994). Participants were asked to state if their pubertal timing was much earlier, somewhat earlier, on time, somewhat later, or much later in relation to their peers. In the sample of girls, $n=3$ reported their pubertal timing as much earlier, $n=8$ as on time, and $n=2$ as somewhat later. In the sample of boys, $n=2$ reported their pubertal timing as much earlier, $n=3$ as somewhat earlier, $n=6$ as on time, and $n=2$ as much later. Higher scores indicate earlier pubertal development. Additionally, adolescent girls were asked about their age at menarche, which was recorded in years and months $(M=12.47, S D=1.76)$. Relative pubertal timing of the girls $(n=13)$ correlated positively with age at menarche (Spearman's $\rho=$ $-.71, p<.01)$. Weichold and Silbereisen (2008) reported analog results with regard to validity. In order to control genetic factors that might predict pubertal timing of girls, mothers were also asked retrospectively about their pubertal timing (relative pubertal timing as well as age at menarche). The correlation of pubertal timing of girls and their mothers $(n=13)$ was statistically insignificant (relative pubertal timing: Spearman's $\rho=.22, p=.46$; age at menarche: Pearson $r=.29, p=.33$ ).

Reproductive strategies. Adolescent girls and boys were surveyed about their reproductive strategies. To assess age at first intercourse and number of sexual partners, participants were supposed to answer two questions: "If you have already had sexual intercourse, how old were you at first intercourse?" (see Bundeszentrale für Gesundheitliche Aufklärung, 2002) and "How many sexual 
partners have you had in your life?"; answers to the latter question were scored as 1, 2, 3-5, 6-10, 11-20, and more than 20 (see Plies \& Schmidt, 1999). In the sample of the girls $(n=8)$ and the boys $(n=9)$, age at first intercourse was $M=15.38, S D=1.19$ years for the girls and $M=15.67$, $S D=1.41$ years for the boys. With regard to the number of sexual partners, the distribution in the sample of girls was $1(n=2), 2(n=5)$, and 3-5 $(n=1)$ and the distribution in the sample of boys was $1(n=5), 2(n=2)$, and 3-5 $(n=2)$.

\section{Results}

To test the hypothesis that family stressors in childhood (father absence, socioeconomic stressors, negative parental relations) are significant predictors of earlier pubertal timing among adolescents, we conducted hierarchical linear regression analyses (Hypothesis 1). We included the independent variables (predictors) of father absence (only for girls) (Step 1), socioeconomic stressors in childhood (Step 2), and parental relations in childhood (the quality of the parents' marital relationship, as well as the quality of the maternal relationship) (Step 3). Prior to these analyses, we examined intercorrelations among the included family stressors. The results indicated no significant associations between these predictors. The analyses were performed separately for girls and boys (Hypothesis 3 ).

Table 1 presents the results of hierarchical linear regression analyses for family stressors in childhood predicting pubertal timing of the girls (using relative pubertal timing and age at menarche as dependent variables). The data displayed in Table 1 show that in both analyses, the quality of the parents' marital relationship was the strongest significant predictor for pubertal timing among the girls $(\beta=-.73$ and $\beta=.60$, respectively). As can be seen, the quality of the parents' marital relationship added a notable amount of explained variance (relative pubertal timing: change in $R^{2}$ for Model $3=.21$; age at menarche: change in $R^{2}$ for Model $3=.20$ ). A negative marital relationship between the parents in childhood predicted an earlier pubertal timing of the girls. Furthermore, Table 1 shows that father absence was also a significant predictor of earlier pubertal timing for girls but only for predicting relative pubertal timing. As can be seen, the effect of father absence was reduced when parental relations in childhood were included.

Table 2 presents the results of hierarchical linear regression analyses for family stressors in childhood predicting pubertal timing of the boys. The data displayed in Table 2 show no significant results. Relative pubertal timing of the boys was not significantly predicted by the examined family stressors in childhood.

To test the hypothesis that pubertal timing of adolescents is a significant predictor both of age at first intercourse and of the number of sexual partners, we conducted linear regression analyses (Hypothesis 2). Separate analyses were performed for girls and boys (Hypothesis 3). The results are presented in Table 3, which shows that pubertal timing of the girls, but not of the boys, was a strong significant predictor of the age at first intercourse in both analyses (relative pubertal timing: $\beta=-.92$, as well as age at menarche: $\beta=.73$ ). Earlier pubertal timing among the girls predicted an earlier age at first intercourse. However, pubertal timing of the adolescent girls and boys did not significantly predict the number of sexual partners.

\section{Discussion}

The aim of this study was to investigate, on the basis of a longitudinal empirical basis comprising a sample of adolescent girls and boys, the predictions of the evolutionary theory of socialization of Belsky et al. (1991a). Specifically, the study examined (1) whether family stressors in childhood (father absence, socioeconomic stressors, negative parental relations) are significant predictors of earlier pubertal timing among adolescents, (2) whether pubertal timing of adolescents is a 
Table I. Hierarchical linear regression analyses for family stressors in childhood predicting pubertal timing of girls $(n=13)^{\mathrm{a}}$.

\begin{tabular}{|c|c|c|c|}
\hline Model & I & 2 & 3 \\
\hline Predictors & $\beta$ & $\beta$ & $\beta$ \\
\hline \multicolumn{4}{|l|}{ Relative pubertal timing ${ }^{\mathrm{b}}$} \\
\hline Father absence ${ }^{c}$ & $.57^{*}$ & $.59^{+}$ & .22 \\
\hline $\begin{array}{l}\text { Socioeconomic stressors in } \\
\text { childhoodd }^{d}\end{array}$ & & -.14 & .09 \\
\hline $\begin{array}{l}\text { Quality of the parents' marital } \\
\text { relationship }{ }^{d}\end{array}$ & & & $-.73^{* *}$ \\
\hline Quality of maternal relationship ${ }^{d}$ & & & .10 \\
\hline$R^{2}$ & $.32 *$ & .33 & $.53^{* *}$ \\
\hline \multicolumn{4}{|l|}{ Age at menarche } \\
\hline Father absence ${ }^{c}$ & -.39 & -.41 & -.04 \\
\hline $\begin{array}{l}\text { Socioeconomic stressors in } \\
\text { childhood }^{d}\end{array}$ & & .19 & .02 \\
\hline $\begin{array}{l}\text { Quality of the parents' marital } \\
\text { relationship }\end{array}$ & & & $.60^{*}$ \\
\hline Quality of maternal relationship ${ }^{d}$ & & & -.04 \\
\hline$R^{2}$ & .16 & .17 & $.36 *$ \\
\hline
\end{tabular}

aResults were analogous even when pubertal timing of mothers of the girls (relative pubertal timing and age at menarche, respectively) was included.

bHigher scores indicate earlier pubertal development.

$c_{n}=13$, father absence was coded as I (both biological parents) and 2 (father absent).

$\mathrm{d}_{n}=12$.

${ }^{+} p<.10 ; *_{p}<.05 ; *^{*} p<.01$.

significant predictor both of age at first intercourse and of the number of sexual partners, and (3) whether the results differ by gender.

For the girls in our sample, the findings were consistent with the theory: Pubertal timing was significantly predicted by the quality of parental relations in childhood (the strongest predictor) and by father absence, and pubertal timing was a significant predictor of the age at first intercourse. Pubertal timing, however, was not a significant predictor of the number of sexual partners.

For the boys in our sample, contrary to the theory's predictions, no significant results were found. The investigated family stressors in childhood did not significantly predict the pubertal timing of the boys, and pubertal timing was also not a significant predictor of the age at first intercourse or of the number of sexual partners.

The results for the girls in our sample support prior prospective longitudinal research findings for predicting pubertal timing in girls, which suggest that the quality of parental relations in childhood may be an important predictor of pubertal timing in girls (Belsky et al., 2007; Ellis \& Essex, 2007; James et al., 2012; Meckelmann, 2008). Chisholm, Burbank, Coall, and Gemmiti (2005) have also noted that

Parents . . have always been the core of their children's 'environment of evolutionary adaptedness' (Bowlby, 1969, p. 50) as they transduced the impact of the larger, more complex, and potentially threatening environments into more buffered, secure versions of those environments for their children (when they could, that is). (p. 91) 
Table 2. Hierarchical linear regression analyses for family stressors in childhood predicting pubertal timing of boys $(n=12)^{\text {a }}$.

\begin{tabular}{lll}
\hline Model & $\mathrm{I}$ & 2 \\
Predictors & $\beta$ & $\beta$ \\
\hline Relative pubertal timing & & \\
Socioeconomic stressors in childhood & $-.1 \mathrm{I}$ & .14 \\
Quality of the parents' marital relationship & & .57 \\
Quality of maternal relationship & & .32 \\
$R^{2}$ & .01 & .35 \\
\hline
\end{tabular}

aBoth biological parents.

bHigher scores indicate earlier pubertal development.

Table 3. Linear regression analyses for pubertal timing predicting age at first intercourse and number of sexual partners among girls $(n=8)$ and boys $(n=9)$.

\begin{tabular}{lcccc}
\hline Predictors & \multicolumn{2}{c}{ Age at first intercourse } & \multicolumn{2}{c}{$\begin{array}{l}\text { Number of sexual } \\
\text { partners }\end{array}$} \\
& $\beta$ & $R^{2}$ & $\beta$ & $R^{2}$ \\
\hline Girls & & & & .25 \\
Relative pubertal timing & $-.92^{* *}$ & $.55^{* *}$ & .50 & .04 \\
Age at menarche & $.73^{*}$ & & -.20 & .01 \\
$\begin{array}{l}\text { Boys } \\
\text { Relative pubertal timinga }\end{array}$ & .03 & .01 & -.10 & \\
\hline
\end{tabular}

aHigher scores indicate earlier pubertal development.

$*_{p}<.05 ; * *_{p}<.01$.

These relations might also explain that socioeconomic stressors in childhood were not found to be a relevant predictor of pubertal timing in our sample of girls; analogous findings were also reported by Ellis et al. (1999). The result that father absence in our sample of girls was only a significant predictor of an earlier relative pubertal timing in relation to peers, but not for predicting age at menarche, might be explained by the fact that these two different measures of pubertal timing also represent different aspects of pubertal timing in girls, regardless of their significant correlation in our sample (Spearman's $\rho=-.71, p<.01$ ). This result supports the findings of the study by Dorn et al. (2003), which indicates that "multiple measures may be necessary to reflect the true process of puberty" (p. 323). In sum, these results for the girls in our sample support the "psychosocial acceleration theory" for predicting pubertal timing in girls (Ellis, 2005, p. 172).

As expected, this study showed that an earlier pubertal timing among girls significantly predicted an earlier age at first intercourse, but contrary to the theory's expected predictions, there was no significant association between pubertal timing of the girls and the number of sexual partners. These results for the girls in our study are in line with the findings of retrospective studies by Hoier (2003a, 2003b) and Neberich et al. (2010), as well as of the prospective longitudinal study by Meckelmann (2008). The findings support the hypothesis that early onset of reproduction and frequent reproduction may be two different aspects of a quantitative reproductive strategy (Chisholm, 1999; Ellis, 2005), as proposed by the "child development theory" (Ellis, 2004, p. 946). 
Contrary to the theory's expected predictions, no significant results were found for the boys in our sample. In line with the prospective longitudinal research findings of Belsky et al. (2007) and James et al. (2012), this may suggest different developmental pathways of girls and boys with respect to the predictions of the evolutionary theory of socialization of Belsky et al. (1991a). Belsky et al. (2007) had also noted that

The fact that when it came to predicting pubertal timing, significant associations emerged only in the case of girls, addresses one of the important questions ..., namely, whether evolutionary analyses of experiential influence on pubertal timing apply equally to boys and girls. (p. 1316)

Our results support a conception of different developmental pathways of girls and boys with respect to the predictions of the evolutionary theory of socialization of Belsky et al. (1991a) and support the hypothesis "that female reproductive development is more sensitive to social experience than is that of males" (Belsky et al., 2007, p. 1305).

Moreover, the fact that we found no significant association between pubertal timing of the girls and their mothers might be explained by the hypothesis of a context-sensitive hereditary transmission of pubertal timing of girls (Chasiotis, 1999). Graber (2003) noted that "correlational studies of correspondence of mothers and daughters for a pubertal event such as menarche include a genetic contribution along with environmental factors" (p. 311). As proposed by Chasiotis, Scheffer, Restemeier, and Keller (1998), in the case of "contextual discontinuity between generations," "no substantial correlation" between the mother's and daughter's pubertal timing may be interpreted as "mainly determined by childhood context" (p. 325). Given the fact that the girls in our sample were born in Berlin during German reunification, which has been described as a time of rapid social change, contextual discontinuity between the childhood experiences of the mother and daughter may be expected. In line with these assumptions, we also found no significant correlation between the parents' marital relationship in the childhood of the girls in our sample and the parents' marital relationship in the childhood of the mothers $(r=.23, p=.45)$.

In sum, the evolutionary theory of socialization of Belsky et al. (1991a) was investigated on the basis of longitudinal empirical evidence derived from a sample of 26 adolescent girls and boys. Our results support the "psychosocial acceleration theory" in its prediction of pubertal timing in girls but not in boys (Ellis, 2005, p. 172). Our findings also support the hypothesis that early onset of reproduction and frequent reproduction may be different aspects of a "quantitative" reproductive strategy (Chisholm, 1999; Ellis, 2005).

James et al. (2012) extended the theory of Belsky et al. (1991a) "by incorporating key principles from sexual selection theory . . . and paternal investment theory" (p. 687). In line with their currently proposed "integrated evolutionary-developmental model of adolescent sexual development and behavior" (James et al., 2012, p. 687), our results also indicate "sex-specific pathways linking ... stressors in and around the family to pubertal maturation, ... . [and] timing of sexual debut" (p. 687).

An important limitation of this study is the extremely small sample size, which reduces the generalizability of our results. Although our results are in line with prior prospective longitudinal research findings, especially for girls, this field of research still needs a larger sample basis and further prospective longitudinal studies that extend from childhood to adolescence and include antecedents of pubertal timing as well as the onset of puberty in relation to subsequent reproductive strategies. Additionally, such future studies should consider the different pathways for girls and boys with respect to the predictions of the evolutionary theory of socialization of Belsky et al. (1991a). Furthermore, future studies for both girls and boys should bear in mind that "multiple 
measures may be necessary to reflect the true process of puberty" (Dorn et al., 2003, p. 323). Another limitation of this study is the retrospective method used to gather reports from adolescent girls and boys on pubertal timing and parental relations in childhood. Despite the fact that there are well-established empirical research findings regarding the high reliability of retrospective reports of age at menarche (see, for review, Ellis \& Essex, 2007), and despite the fact that our results are in line with other prospective longitudinal studies (Belsky et al., 2007; Ellis \& Essex, 2007; Meckelmann, 2008), future studies are necessary to verify the results of this study.

In conclusion, with regard to implications for education and counseling, the results of our study indicate the relevance of the quality of family relations in childhood (in terms of warmth and trustfulness) for the development of children and adolescents. Moreover, in line with James et al. (2012), the results of our study also point to "distinct developmental influences on male and female sexual behavior" (p. 699). ${ }^{3}$

\section{Declaration of conflicting interests}

The authors declare that they do not have any conflict of interest.

\section{Funding}

This research received no specific grant from any funding agency in the public, commercial, or not-for-profit sectors.

\section{Notes}

1. "Adrenarche has been described as the 'awakening of the adrenal glands' and occurs at approximately 6-8 years of age in both boys and girls (Dorn \& Chrousos, 1997; Grumbach \& Styne, 2003)" (Ellis \& Essex, 2007, p. 1803).

2. The aim of the original project "Berliner Wendekinder" was to examine the impact of the sociopolitical changes during German reunification on the development of children from two different birth cohorts, namely, those born in former East and West Berlin. The children in the older cohort were born before German reunification (1985-1986). The children of the younger cohort were born during the period of German reunification (1988-1990). The sociopolitical changes during German reunification "can be described as a change in the typical characteristics of a society, such as social structures and institutions, norms, [and] values" (Calhoun, 1992, as cited in Silbereisen, 2005, p. 2). According to Elder (1974), children experience social changes mediated by their parents. Correspondingly, in the context of the original project "Berliner Wendekinder," mothers' experiences of the sociopolitical changes in Berlin were also being investigated. In the context of the theoretical predictions of the theory of Belsky et al. (1991a), mothers exhibited greater emotional insecurity during the first period of sociopolitical changes in relation to the time before German reunification, especially among mothers from former East Berlin. The children were investigated in the transition from preschool to elementary school. Overall, the children of the younger cohort (who were born during the period of German reunification) showed more problem behavior than the older cohort.

3. This article is based on a poster presented at the XXIX International Congress of Psychology in Berlin, Germany, in July 2008.

\section{References}

Belsky, J. (1999). Modern evolutionary theory and patterns of attachment. In J. Cassidy, \& P. Shaver (Eds.), Handbook of attachment theory and research (pp. 141-161). New York, NY: Guilford Press.

Belsky, J., Steinberg, L., \& Draper, P. (1991a). Childhood experience, interpersonal development, and reproductive strategy: An evolutionary theory of socialization. Child Development, 62, 647-670.

Belsky, J., Steinberg, L., \& Draper, P. (1991b). Further reflections on an evolutionary theory of socialization. Child Development, 62, 682-685. 
Belsky, J., Steinberg, L. D., Houts, R. M., Friedman, S. L., DeHart, G., Caufman, E. . . The NICHD Early Child Care Research Network. (2007). Family rearing antecedents of pubertal timing. Child Development, 78, 1302-1321.

Belsky, J., Steinberg, L., Houts, R. M., \& Halpern-Felsher, B. L. (2010). The development of reproductive strategy in females: Early maternal harshness $\rightarrow$ earlier menarche $\rightarrow$ increased sexual risk taking. Developmental Psychology, 46, 120-128.

Bogaert, A. F. (2005). Age at puberty and father absence in a national probability sample. Journal of Adolescence, 28, 541-546.

Bundeszentrale für Gesundheitliche Aufklärung. (Hrs.). (2002). Jugendsexualität: Wiederholungsbefragung von 14-17-Jährigen und ihren Eltern; Ergebnisse der Repräsentativbefragung aus 2001 [Youth sexuality 2001. Results of a representative survey conducted in 2001]. Köln, Germany: BZgA Abt. Sexualaufklärung, Verhütung und Familienplanung.

Chasiotis, A. (1999). Kindheit und Lebenslauf. Untersuchungen zur evolutionären Psychologie der Lebensspanne [Childhood and lifespan. Investigations on evolutionary psychology]. Bern, Switzerland: Huber.

Chasiotis, A., \& Keller, H. (1995). Kulturvergleichende Entwicklungspsychologie und evolutionäre Sozialisationsforschung [Cross cultural developmental psychology and evolutionary socialization research]. In G. Trommsdorff (Ed.), Kindheit und Jugend in verschiedenen Kulturen. Entwicklung und Sozialisation in kulturvergleichender Sicht (pp. 21-42). Weinheim, Germany: Juventa.

Chasiotis, A., Scheffer, D., Restemeier, R., \& Keller, H. (1998). Intergenerational context discontinuity affects the onset of puberty. A comparison of parent-child dyads in West and East Germany. Human Nature, 9, 321-339.

Chisholm, J. S. (1999). Attachment and time preference. Relations between early stress and sexual behaviour in a sample of American university women. Human Nature, 10, 51-83.

Chisholm, J. S., Burbank, V. K., Coall, D. A., \& Gemmiti, F. (2005). Early stress: Perspectives from developmental evolutionary ecology. In B. J. Ellis, \& D. F. Bjorklund (Eds.), Origins of the social mind. Evolutionary psychology and child development (pp. 76-107). New York, NY: Guilford Press.

Dorn, L. D., Dahl, R. E., Williamson, D. E., Birmaher, B., Axelson, D., Perel, J., . . Ryan, N. D. (2003). Developmental markers in adolescence: Implications for studies of pubertal processes. Journal of Youth and Adolescence, 32, 315-324.

Elder, G. H. Jr. (1974). Children of the great depression. Chicago, IL: The University of Chicago Press.

Ellis, B. J. (2004). Timing of pubertal maturation in girls: An integrated life history approach. Psychological Bulletin, 130, 920-958.

Ellis, B. J. (2005). Determinants of pubertal timing. An evolutionary developmental approach. In B. J. Ellis, \& D. F. Bjorklund (Eds.), Origins of the social mind. Evolutionary psychology and child development (pp. 164-188). New York, NY: Guilford Press.

Ellis, B. J., \& Essex, M. J. (2007). Family environment, adrenarche, and sexual maturation: A longitudinal test of a life history model. Child Development, 78, 1799-1817.

Ellis, B. J., \& Garber, J. (2000). Psychosocial antecedents of variation in girl's pubertal timing: Maternal depression, stepfather presence, and marital and family stress. Child Development, 71, 485-501.

Ellis, B. J., McFadyen-Ketchum, S., Pettit, G. S., Dodge, K. A., \& Bates, J. E. (1999). Quality of early family relationships and individual differences in the timing of pubertal maturation in girls: A longitudinal test of an evolutionary model. Journal of Personality and Social Psychology, 77, 387-401.

Fend, H. (1994). Die Entdeckung des Selbst und die Verarbeitung der Pubertät. Entwicklungspsychologie der Adoleszenz in der Moderne [Discovery of self and handling puberty. Developmental psychology of adolescence] (Bd. III). Bern, Switzerland: Huber.

Graber, J. A. (2003). Puberty in context. In C. Hayward (Ed.), Gender differences at puberty (pp. 307-325). Cambridge, UK: Cambridge University Press.

Hayward, C. (Ed.). (2003). Gender differences at puberty. Cambridge, UK: Cambridge University Press.

Hoier, S. (2003a). Das frühe erste Mal: Familie, Pubertät und Partnerschaft. Eine evolutionspsychologische Untersuchung [The early first time: Family, puberty, and partnership. An evolutionary investigation]. Lengerich, Germany: Pabst Science. 
Hoier, S. (2003b). Father absence and age at menarche. A test of four evolutionary models. Human Nature, 14, 209-233.

James, J., Ellis, B. J., Schlomer, G. L., \& Garber, J. (2012). Sex-specific pathways to early puberty, sexual debut, and sexual risk taking: Tests of an integrated evolutionary-developmental model. Developmental Psychology, 48, 687-702.

Keller, H., \& Chasiotis, A. (2006). Zur natürlichen und geschlechtlichen Selektion der menschlichen Individualentwicklung [Natural and mate selection in human ontogenetic development]. In W. Schneider, \& F. Wilkening (Eds.), Theorien, Modelle und Methoden der Entwicklungspsychologie (Enzyklopädie der Psychologie, Serie Entwicklungspsychologie, Bd. 1, pp. 509-551). Göttingen, Germany: Hogrefe.

Kim, K., \& Smith, P. K. (1998). Retrospective survey of parental marital relations and child reproductive development. International Journal of Behavioral Development, 22, 729-751.

Kim, K., \& Smith, P. K. (1999). Family relations in early childhood and reproductive development. Journal of Reproductive and Infant Psychology, 17, 133-148.

Meckelmann, V. (2008). Kindheitserfahrungen, körperliches Entwicklungstempo in der Pubertät und Reproduktionsstrategien bei weiblichen Jugendlichen - eine prospektive Längsschnittstudie [Childhood experiences, pubertal timing, and reproductive strategies of adolescent girls - A prospective longitudinal study]. Psychologie in Erziehung und Unterricht, 55, 211-222.

Moffitt, T. E., Caspi, A., Belsky, J., \& Silva, P. (1992). Childhood experience and the onset of menarche: A test of a sociobiological model. Child Development, 63, 47-58.

Neberich, W., Penke, L., Lehnhart, J., \& Asendorpf, J. B. (2010). Family of origin, age at menarche, and reproductive strategies: A test of four evolutionary-developmental models. European Journal of Developmental Psychology, 7, 153-177.

Petersen, A. C., Crockett, L. J., Richards, M. H., \& Boxer, A. (1988). A self-measure of pubertal status: Reliability, validity and initial norms. Journal of Youth and Adolescence, 17, 117-133.

Plies, K., \& Schmidt, P. (1999). Sex und Partnerschaft, sexuelle Kompetenz und Sexualdemographie [Sex and partnership, sexual competence, and sexual demography]. In K. Plies,, B. Nickel, \& P. Schmidt (Eds.), Zwischen Lust und Frust. Jugendsexualität in den 90er Jahren (pp. 41-67). Leverkusen, Germany: Leske + Budrich.

Rauh, H., Weber, C., Feger, H., \& Doerfel-Baasen, D. (1999). Berliner Wendekinder [Berlin children of reunification] (Unveröffentlichter Abschlussbericht des DFG-Projektes "Kindheit und Jugend in Deutschland vor und nach der Vereinigung-Entwicklungsbedingungen und Lebenslagen im Wandel"). Institut für Psychologie der Universität Potsdam, Potsdam, Germany.

Saxbe, D. E., \& Repetti, R. L. (2009). Brief report: Fathers' and mothers' marital relationship predicts daughters' pubertal development two years later. Journal of Adolescence, 32, 415-423.

Scheffer, D., Chasiotis, A., Restemeier, R., Keller, H., \& Schölmerich, A. (2000). Retrospektive Erfassung frühkindlicher Beziehungsaspekte: Konstruktion der Beziehungs-Kontext-Skala [Retrospective measurement of representational aspects of childhood relationships: Construction of the Relationship Context Scale]. Zeitschrift für Entwicklungspsychologie und Pädagogische Psychologie, 32, 2-13.

Silbereisen, R. K. (2005). Presidential address: Social change and human development: Experiences from German unification. International Journal of Behavioral Development, 29, 2-13.

Surbey, M. K. (1998). Parent and offspring strategies in the transition at adolescence. Human Nature, 9 , 67-94.

Tither, J. M., \& Ellis, B. J. (2008). Impact of fathers on daughters' age at menarche: A genetically and environmentally controlled sibling study. Developmental Psychology, 44, 1409-1420.

Tremblay, L., \& Frigon, J.-Y. (2005). Precocious puberty in adolescent girls: A biomarker of later psychosocial adjustment problems. Child Psychiatry \& Human Development, 36, 73-94.

Weichold, K., \& Silbereisen, R. K. (2008). Pubertät und psychosoziale Anpassung [Puberty and psychosocial adjustment]. In R. K. Silbereisen, \& M. Hasselhorn (Eds.), Entwicklungspsychologie des Jugendalters (Enzyklopädie der Psychologie. Serie Entwicklungspsychologie, Bd. 5, pp. 3-53). Göttingen, Germany: Hogrefe. 